\title{
Cardiac tamponade and hypothyroidism
}

\section{Lujza Grueva*, Elena G. Nastevska}

University Clinic of Cardiology, Skopje, Republic of North Macedonia
KEYWORDS: hypothyroidism, pericardial effusion.

CITATION: Cardiol Croat. 2019;14(3-4):65. | https://doi.org/10.15836/ccar2019.65

*ADDRESS FOR CORRESPONDENCE: Lujza Grueva, University Clinic of Cardiology Vodnjanska 17, 1000 Skopje, Republic of North Macedonia.

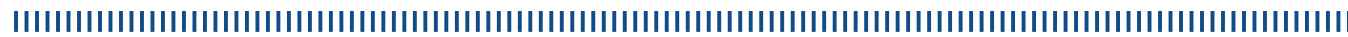

Introduction: Hypothyroidism is one of the most common diseases in endocrinology, which can be diagnosed easily with the current diagnostic procedures and a typical clinical expression. One of the most frequent cardiological complication of hypothyroidism is the pericardial effusion, with incidence of $30-75 \%$, while the heart tamponade is a very rare complication that requires urgent treatment. ${ }^{1}$

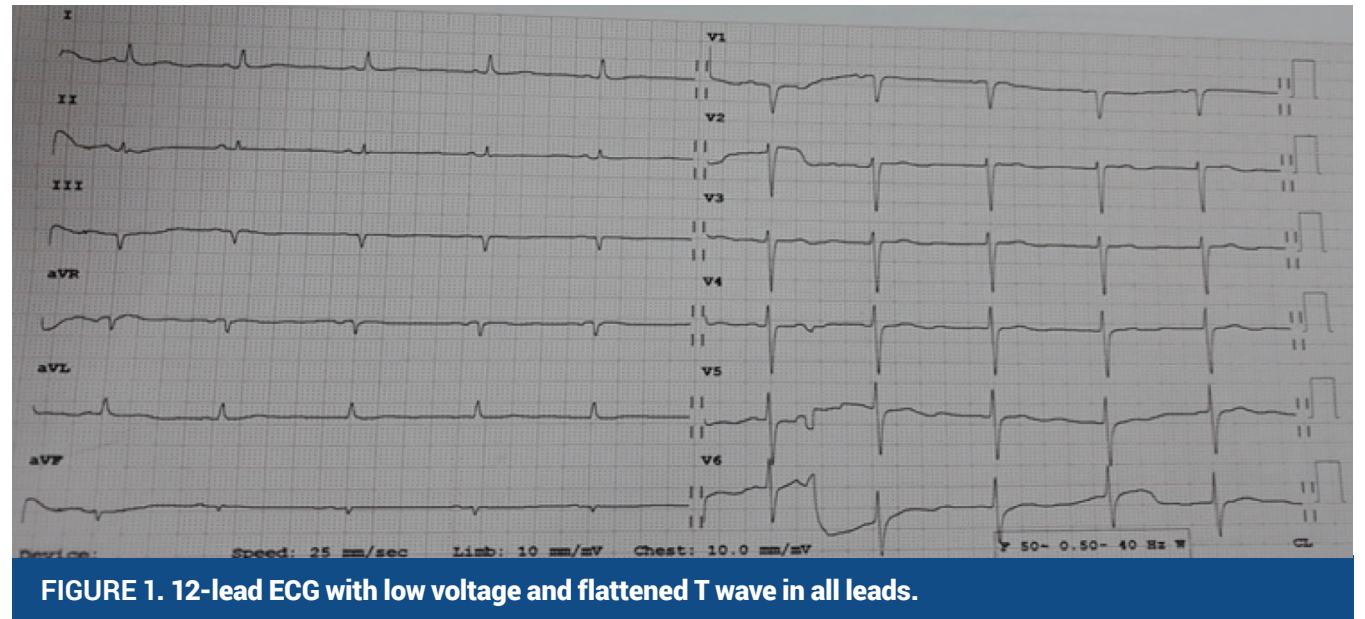

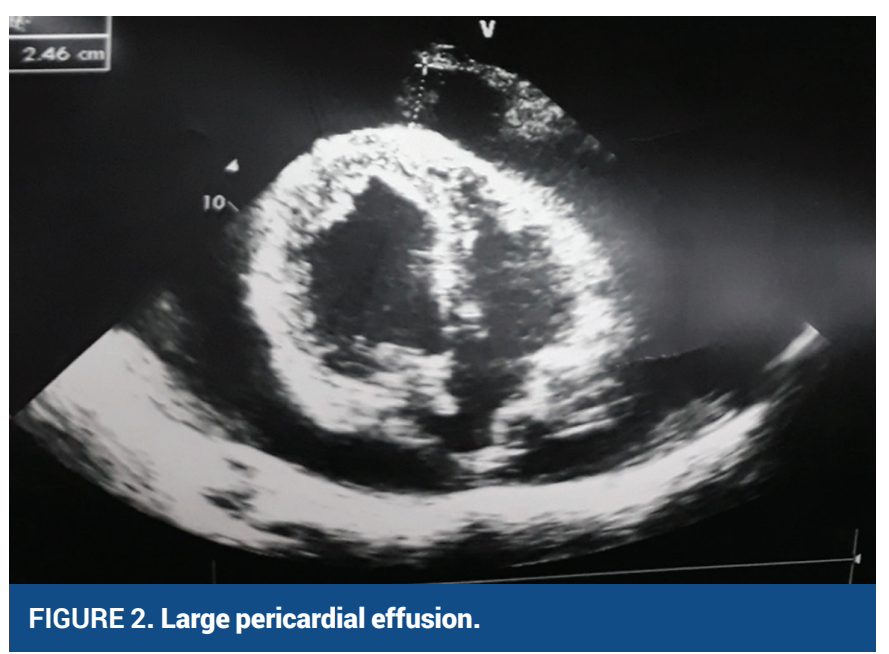

RECEIVED:

February 28, 2019

ACCEPTED:

March 24, 2019

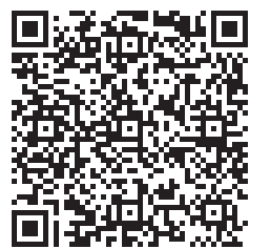
treatment.

https://doi.org/10.4103/2230-8210.123560
Case report: 60-year-old woman was admitted to the clinic of Cardiology in Skopje, dyspneic with a general malaise. During the physical exam the patient was with slower speech, dry skin and hair, brittle nails, bilateral periorbital edema. Vital signs: heart rate 85 beats per minute, blood pressure 180/100mmHg 12-lead ECG findings showed low voltage and flattened $\mathrm{T}$ wave in all leads (Figure 1). During the echocardiography exam (Figure 2) was confirmed a large pericardial effusion with a compression on the right-sided cavities and a "swinging heart", and pericardiocentesis was indicated. More than $1100 \mathrm{ml}$ of fluid was evacuated and sent for further investigations. Laboratory findings showed advanced and untreated hypothyroidism (TSH $>75.0 \mathrm{ulU} / \mathrm{ml}$, free T4 <3.86 pmol/L; total T4 <12.9 nmol/L).

Conclusion: The amount of pericardial effusion (PE) in patients with hypothyroidism is correlated with the progress of the disease, and is very common in myxedema, but very rare in mild forms of hypothyroidism. In Macedonia, especially in the rural environments, patients with hypothyroidism are mostly undiagnosed on time, so the complications are more frequent. Effective and on time diagnose of PE is crucial, because of the high risk of cardiac tamponade. Positive outcome and hemodynamic stability in most of the patients with hypothyroidism is achieved after the application of appropriate thyroxin

LITERATURE IIIIIIIIIIIIIIIIIIIIIIIIIIIIIIIIIIIIIIIIIIIIIIIIIIIIIIIIIIIIIIIIIIIIIIIIIIIIIIIIIIIIIIIIIIIIIIIIIIIIIIII

1. Mokta J, Mokta K, Panda P, Sharma M, Bhatia V. A swinging heart. Indian J Endocrinol Metab. 2013 Dec;17(Suppl 3):S660-1. 